\title{
10. SPECTRAL STUDIES OF METEORS \\ AT THE TOKYO ASTRONOMICAL OBSERVATORY
}

\author{
H. Hirose, K. Nagasawa, and K. Tomita \\ (Tokyo Astronomical Observatory, Mitaka, Japan)
}

\section{Introduction}

Our program of meteor research has been changed since November, 1963, by introducing spectral photography at the Dodaira branch station of the Tokyo Astronomical Observatory, in addition to the direct photography at the Mitaka Station. Observations at these two stations are basic, and they have been supplemented in case of need by observations at the temporary station at Tatebayashi, situated about $40 \mathrm{~km}$ Northeast of Dodaira. Double- or triple-station observations were carried out mainly during the active period of the major streams, such as Quadrantids, Perseids, Leonids or Geminids, with the purpose of the dynamical and physical studies of meteors. The coordinates of these three stations are as given in Table 1.

\section{Table 1}

\section{Coordinates of stations}

$\begin{array}{lllr} & \text { Longitude } & \text { Latitude } & \text { Height } \\ \text { Dodaira } & 139^{\circ} 11^{\prime} 37^{\prime \prime} & 36^{\circ} 00^{\prime} 10^{\prime \prime} & 876^{\mathrm{m}} \\ \text { Mitaka } & 139^{\circ} 32^{\prime} 30^{\prime \prime} & 35^{\circ} 40^{\prime} 11^{\prime \prime} & 60^{\mathrm{m}} \\ \text { Tatebayashi } & 139^{\circ} 30^{\prime} 05^{\prime \prime} & 36^{\circ} 15^{\prime} 27^{\prime \prime} & 22^{\mathrm{m}}\end{array}$

This report contains the outline of the program with a short description of the instruments used and the partial results concerning the spectrograms obtained up to the present.

\section{The Equipment and Research Procedure}

The direct purpose of our observation program is to take good meteor spectrograms supported by photographic double- or triple-station data. We employed three types of cameras for this purpose, i.e. fixed spectro-cameras, equatorially mounted direct cameras, and small fixed wide-angle cameras for the timing of the meteors' apparitions.

All the spectro-cameras are installed at Dodaira. They have prisms or transmission gratings of various dispersion values, $1500 \AA / \mathrm{mm}-170 \AA / \mathrm{mm}$, in front of the camera 
lenses. Direct photography cameras are equatorially mounted automatic ones specially designed by us and are installed at Dodaira and Mitaka (Figure 1). Each camera consists of four camera lenses arranged so as to photograph the adjoining sky fields, $60^{\circ} \times 80^{\circ}$ in total, on two rolls of film of aerial photography instead of photographic plates. This will evidently weaken the conservation of position on the photograph

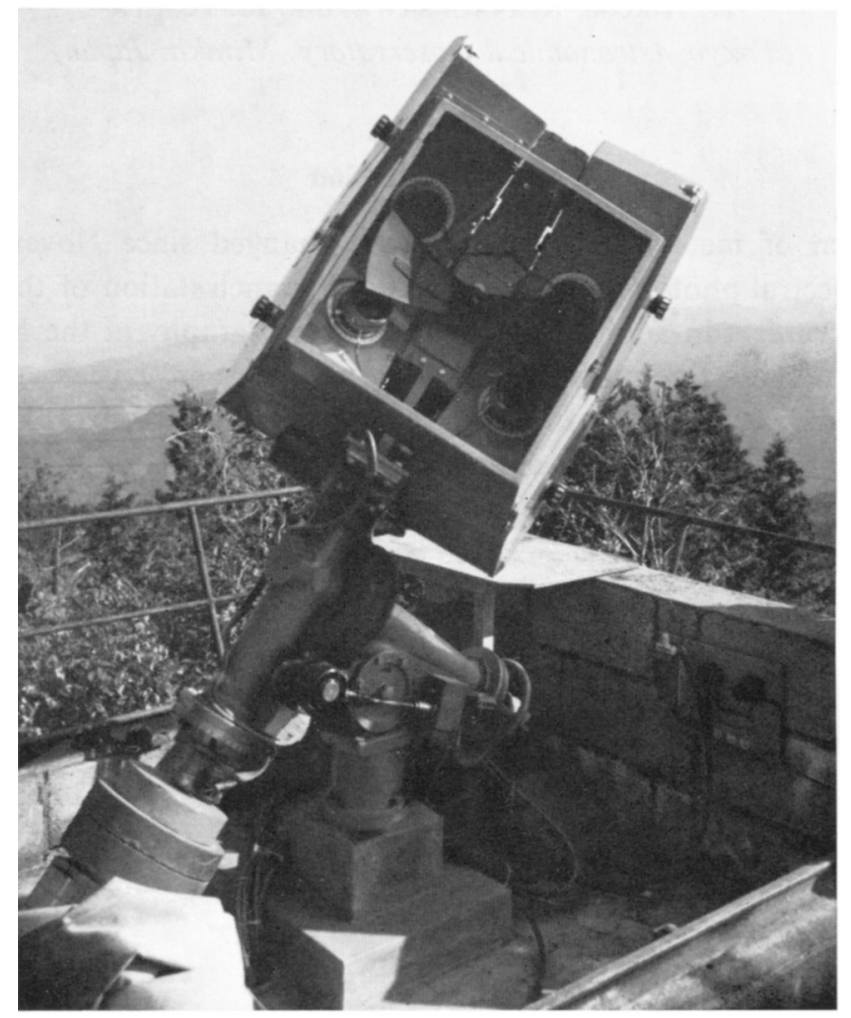

Fig. 1. Automatic Meteor Camera 'A' (Dodaira Station).

but, according to our experience, our film-backing device, with the use of vacuum suction, has proved to be satisfactory. Roll-film is far more convenient than photographic plates for converting cameras into automatic loading ones. Moreover, we think that the collection of more data in an efficient way is far more important than to secure relatively more precise spectrograms, or direct photographs, with the use of photographic plates. The ease in obtaining high-sensitive and suitable photographic emulsions in the form of film was also a reason why we had to change our policy on meteor photography and spectroscopy.

The camera can be operated (partially programmed) under a remote-control 
system. The camera setting and the selection of the exposure duration can be performed or programmed at the control panel, and the film is automatically shifted by one frame during the movement of the camera for the next setting, after the completion of the desired length of the exposure. The times of the beginning and ending of the exposure are photographically recorded on the same meteor film. The rotating shutter is operated by an accurate oscillator.

Up to the present, these automatic cameras have been used almost exclusively for direct photography, but we plan to convert them into grating cameras, as the zero-order image of such a camera is as satisfactory as direct photography, allowing for the loss of light intensity.

General data about our cameras are summarized in Table 2.

Table 2

\section{Instrumental data}

Designation Aperture Focal length Field area Type of Dispersion System Dispersion "

\begin{tabular}{lccclc}
\multicolumn{7}{c}{ Fixed Spectrocamera (at Dodaira) } \\
NT & $11 \mathrm{~cm}$ & $50 \mathrm{~cm}$ & $22^{\circ} \times 18^{\circ}$ & Prism BK7 22 & $450 \AA / \mathrm{mm}$ \\
G & 7 & 30 & $35 \times 29$ & Prism F3 26 & 260 \\
K-20 & $5 \cdot 7$ & 20 & $39 \times 30$ & Prism BK7 46 & 385 \\
NA & $5 \cdot 7$ & 20 & $35 \times 27$ & Grating $150 \mathrm{grv} / \mathrm{mm}^{\mathrm{a}}$ & 320 \\
NB & $5 \cdot 7$ & 20 & $35 \times 27$ & Grating 150 & 320 \\
NC & $5 \cdot 7$ & 20 & $35 \times 27$ & Grating 300 grv/mm & 170 \\
ND & $5 \cdot 7$ & 20 & $35 \times 27$ & Grating 300 & 170 \\
A & Four-lens Photo Camera & & & (at Dodaira) \\
B & $5 \cdot 7$ & 20 & $60 \times 80$ & (at Mitaka) & (at Dodaira) \\
$t$ & $5 \cdot 7$ & 20 & $60 \times 80$ &
\end{tabular}

a Blazed for maximum intensity near $6000 \AA$ in the first order on one side.

b Mean value, $\boldsymbol{H} \gamma \sim \boldsymbol{H} \delta$.

\section{Observations, Analysis and Results in General}

We have made observations on 80 nights, about 350 hours in total. The number of meteor spectra secured throughout the period amounts to 79, as given in Table 3 . About one-half of these spectra were obtained during the active period of the Leonids in 1965, and the rest consist of the Leonids of 1963 and 1964, Perseids, Taurids, Geminids, and sporadics. Some specimens of our meteor spectra are reproduced here as Figures 2-4.

The bright meteor shown as Figure 3 (spectrum No. 50) appeared on the night of November 16, 1965. This was brighter than the full moon and left its train for over $10 \mathrm{~min}$. The train was also photographed by many amateur observers in Japan. 


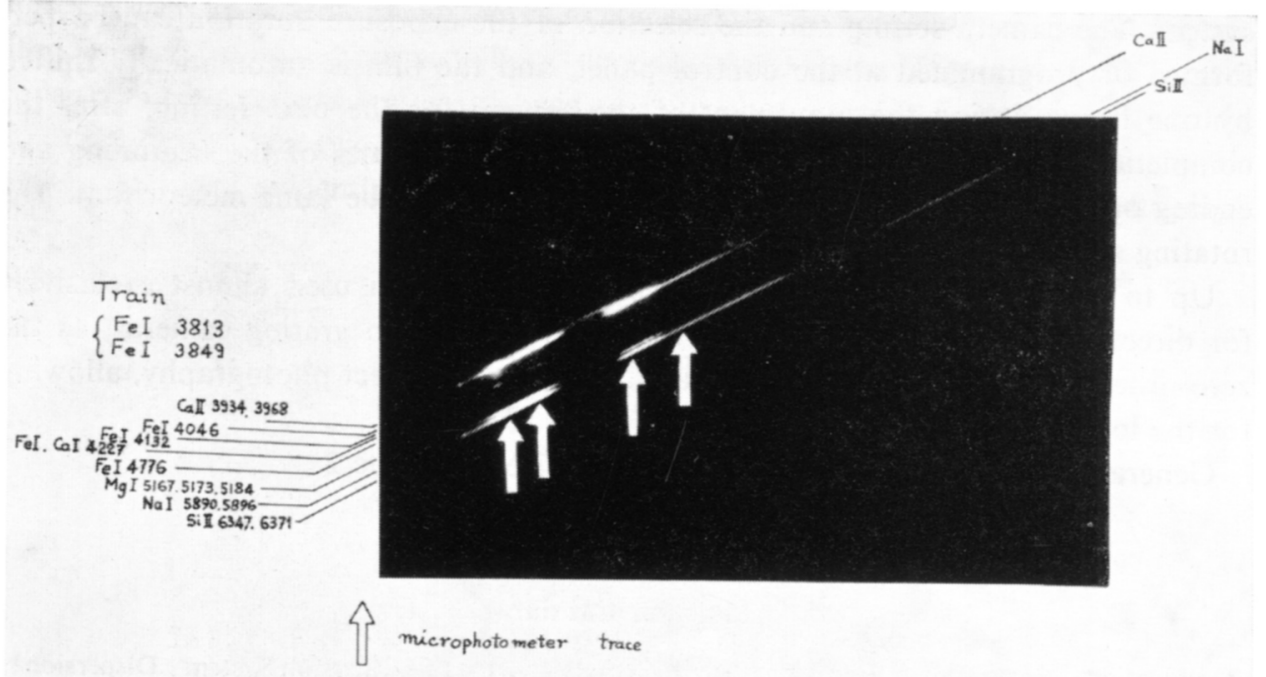

Fig. 2. Prismatic spectrum No. 11 (Aug. 12, 1964). Photometric tracings are indicated by arrows.

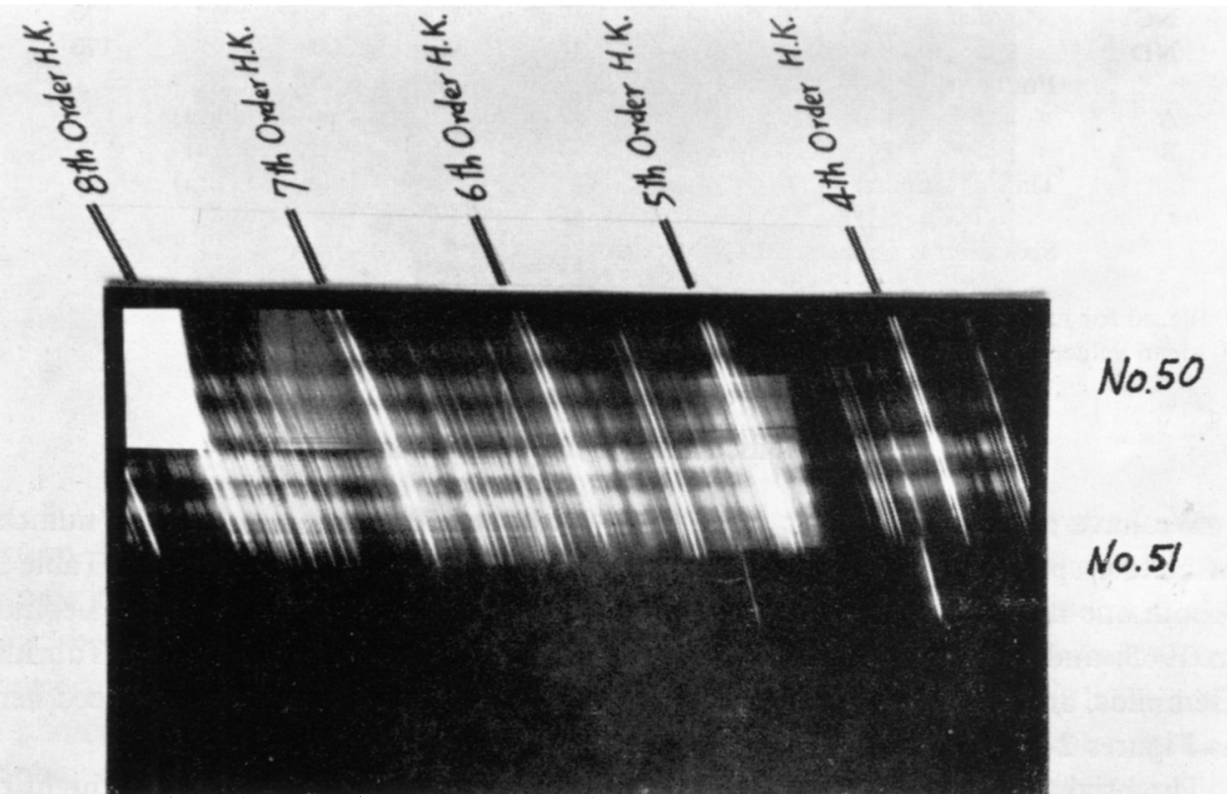

Fig. 3. Higher-order grating spectra of a bright meteor, No. 50 (Nov. 16, 1965). A faint spectrum of another meteor, No. 51, is also recorded in the same frame. 


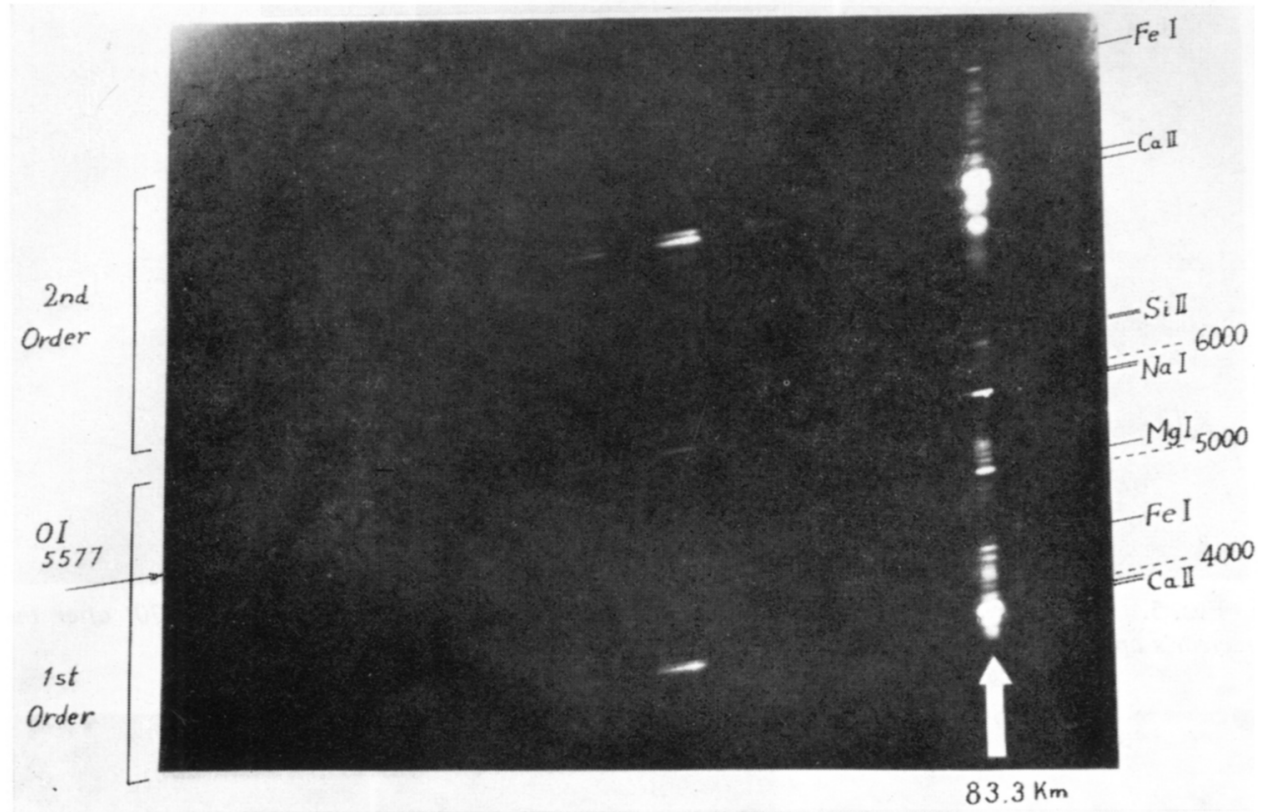

Fig. 4. Grating spectrum No. 59 of a flaring meteor (Nov. 16, 1965). The height of the flare (arrow) is $83.3 \mathrm{~km}$.

Table 3

\section{Statistics of our spectra}

\begin{tabular}{lccccr}
\multicolumn{1}{r}{ Stream } & \multicolumn{5}{c}{ Number of Lines } \\
& 50 & $49-20$ & $19-10$ & $9-1$ & Total \\
Perseids & - & - & 2 & 12 & 14 \\
Taurids & - & - & - & 2 & 2 \\
Leonids & 6 & 1 & 6 & 25 & 38 \\
Geminids & - & 3 & 1 & 11 & 15 \\
Sporadics & - & - & - & 10 & 10 \\
Total & 6 & 4 & 9 & 60 & 79
\end{tabular}

Photographs, such as Figures 5 and 6, have been analysed by Mr. Keiji Saito of our Observatory. His detailed discussion will be published by him elsewhere in the near future. However, we quote here his partial result on the variation of the wind's direction and velocity as a function of height. Mr. Saito drew a hodographic figure concerning this problem, reproduced here as Figure 7. Fourth- to eighth-order grating spectra of this meteor have also been secured at Dodaira by us, but the analysis has not yet been completed.

Our usual process of analysis of a good spectrogram is as follows:

(a) The identification of the observed emission lines 

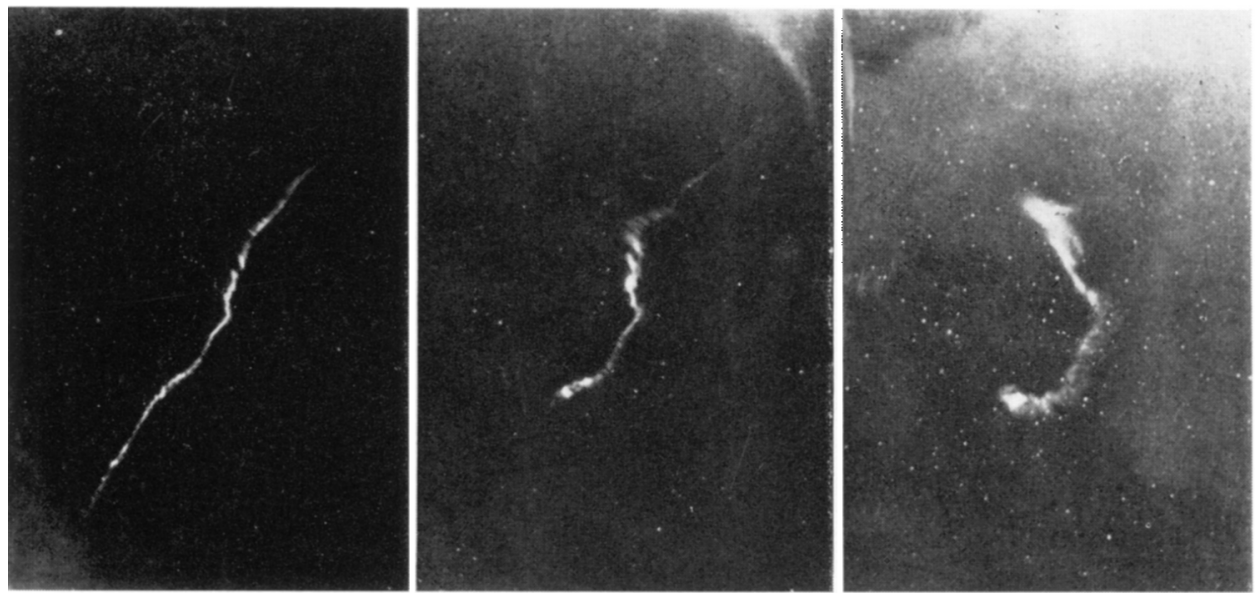

Fig. 5. Variation of the train of a bright meteor photographed about $30^{\circ}, 50^{\circ}$ and $70^{8}$ after the meteor's apparition (left to right). (Photograph by Mr. Y. Hirano of Ashikaga.)
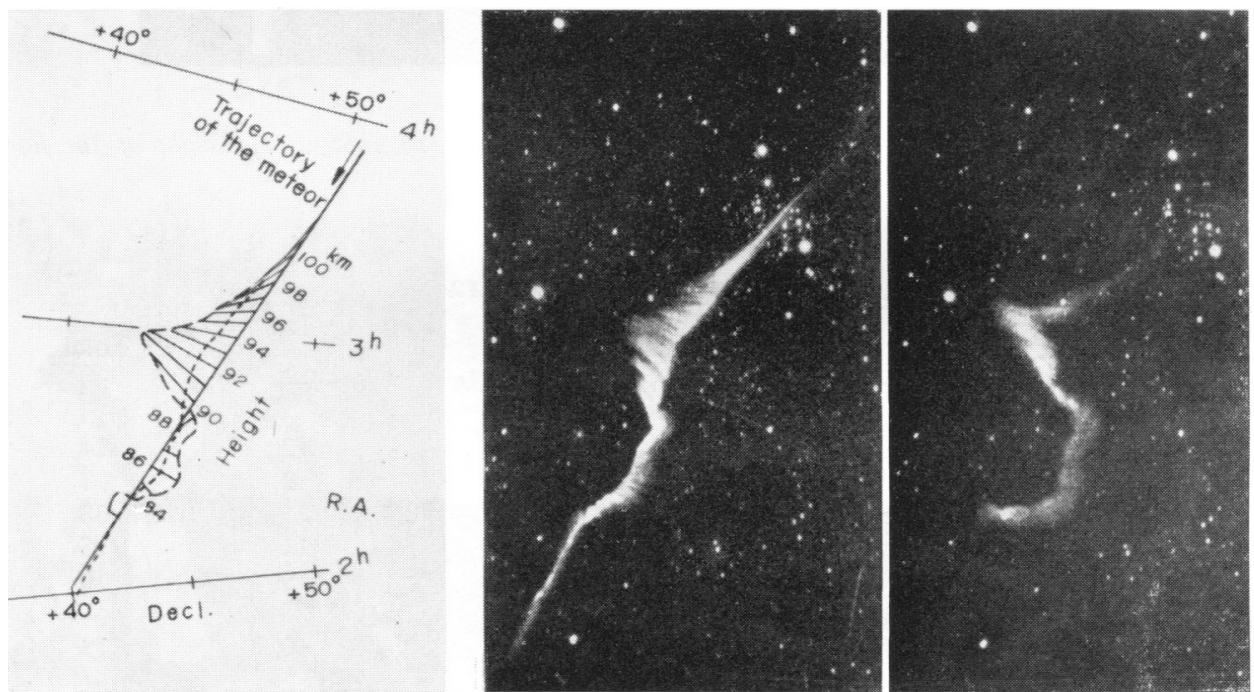

Fig. 6. Variation of the train of a bright meteor photographed about $48^{8}$ and $92^{8}$ after the meteor's apparition (middle to right). The left diagram shows two photographs in one. Height, right ascension and declination are also indicated. (Photograph by Mr. K. Asoya of Utsunomiya.)

(b) The photometric analysis to determine the energy distribution of the meteor radiation with wavelength;

(c) The attempt for the determination of the temperature and chemical composition, as related to the radiation, assuming local thermal equilibrium;

(d) The determination of the local and heliocentric orbit and velocity of the 


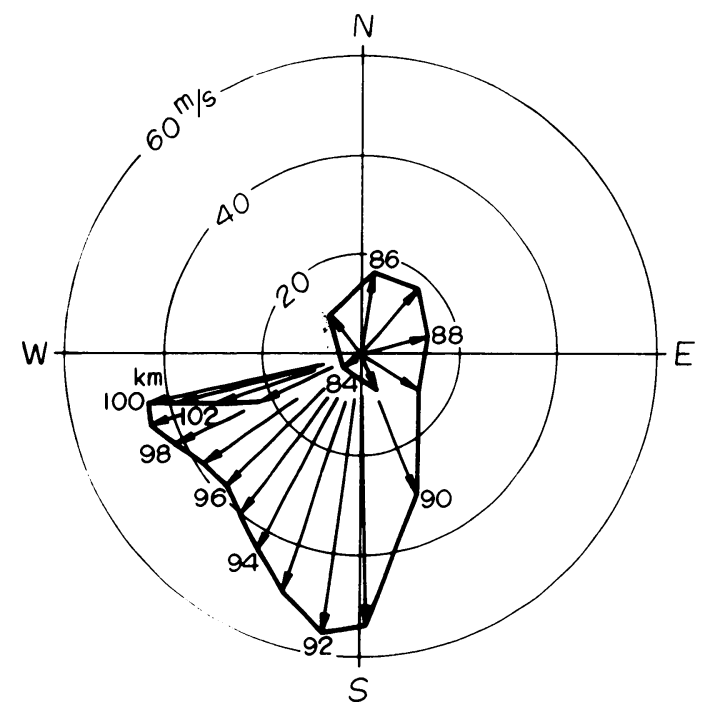

FIG. 7. Hodograph of the wind-velocity vector. The direction of the wind, together with its velocity, is shown as a function of height.

meteor concerned, based on the double- or triple-station photographic observations, to investigate the relations between the radiation and the meteor's height.

Through the analysis of selected spectrograms, as given above, the following general results have been obtained from our meteor spectra:

(a) On the spectrograms of the fast meteors, such as Leonids and Perseids, Ca II $\mathrm{H}$ and $\mathrm{K}$ lines are generally the strongest. But, after carrying out the correction for the spectral sensitivity, SiII lines at $6347 \AA$ and $6371 \AA$ seem to become stronger than the others. In general, these two silicon lines do not appear so strong because they are located in a region of quite low sensitivity for the normal panchromatic emulsion. To confirm the fact, we are now planning to take meteor spectrograms with the use of an infrared film.

(b) Other lines appearing on the spectrograms of the fast meteors are those of $\mathrm{NaI}, \mathrm{MgI}$ and FeI. In the case of the very bright meteor, the lines of CoI, CrI, NiI and the forbidden line of Or (5577 $\AA$ ) are observed.

(c) In the case of the slow meteors, such as Geminids, nearly all the lines are identified with FeI except for the $\mathrm{D}$ lines of $\mathrm{NaI}$.

(d) Though the variation of line intensities, increase or decrease, generally takes place nearly simultaneously for every spectral line, the rate of the variation is not always equal. Only the forbidden line of OI ( $5577 \AA$ ) shows quite peculiar aspects, appearing long before the other lines, i.e. at the great height of over $100 \mathrm{~km}$, and disappearing first.

(e) From the previous results of our analysis, we do not think a reliable temperature 
of the meteor was obtained. As for the chemical composition, it seems that silicon is the most abundant element in fast meteors.

(f) We cannot yet decide if the differences in the spectra of the fast and the slow meteors respectively are due to the velocity difference between these two groups or to their original compositions.

(g) It might be worth while to note that the heights of the points where a meteor flared and darkened seemed to coincide with the layers where the wind was of zero velocity. This fact should be carefully studied with the use of more material.

\section{On the Spectrum of a Leonid Meteor}

During our Leonid observation period, a fairly bright meteor appeared at $18^{\mathrm{h}} 21^{\mathrm{m}}$ UT, November 16, 1965, in the Southwest sky at Dodaira station. The magnitude was estimated as about -5 . Fortunately, we secured a grating spectrogram (spectrum No. 56) with the fixed camera NB. The quality of the spectrogram was good enough to carry out further analysis. This is shown as Figure 8. On this spectrogram one can easily see the forbidden line of OI $(5577 \AA)$ at the left side. Table 4 gives observational data for spectrum No. 56.

Neither cameras at Mitaka nor those at Tatebayashi could record the meteor's

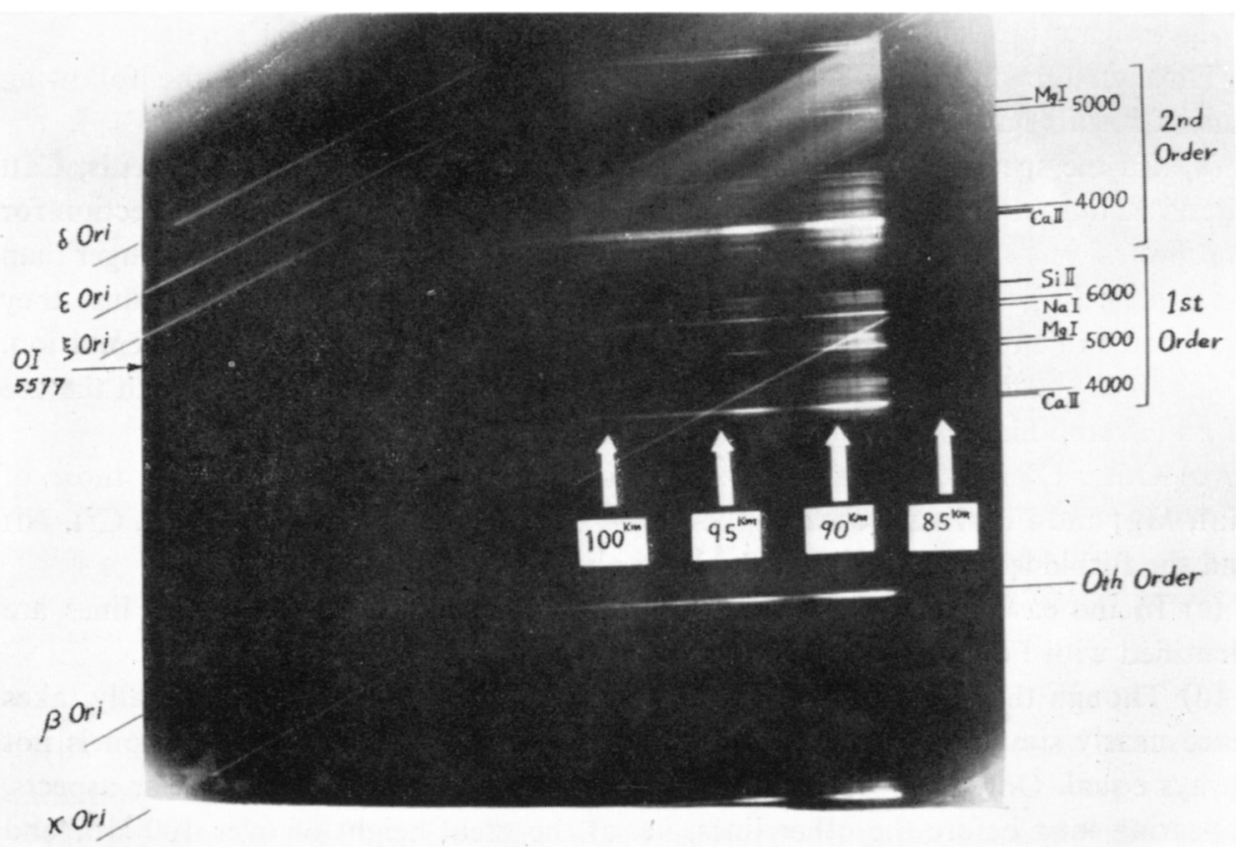

Fig. 8. Spectrum No. 56 (Nov. 16, 1965, $18^{h} 21^{m}$ UT). Heights of various points are indicated by arrows. 
Table 4

\section{Observational data of Spectrum No. 56}

Station: Dodaira

Exposure: 1965 Nov. $16,18^{\mathrm{h}} 20^{\mathrm{m}} 15^{\mathrm{s}}-18^{\mathrm{h}} 47^{\mathrm{m}} 15^{\mathrm{s}}$ (UT)

Angle between the meteor's path and the direction of the dispersion: $87^{\circ}$

Appearance: $\quad$ R.A. $5^{\mathrm{h}} 50^{\mathrm{m}} .5$ Decl. $-7^{\circ} 18^{\prime} \quad(1950.0)$

Disappearance: R.A. $4^{\mathrm{h}} 51^{\mathrm{m}} \cdot 5$ Decl. $-13^{\circ} 6^{\prime} \quad(1950.0)$

Brightest Point (R.A. 4 $58^{\mathrm{m}}$.0 Dect. $-12^{\circ} 22^{\prime} \quad(1950 \cdot 0)$

Brightest Point ; Azimuth from South: $41^{\circ} 35^{\prime}$, Altitude $31^{\circ} 8^{\prime}$

Photographic Film: Tri-X (ASA400), $10 \times 12.5 \mathrm{~cm}$, pack film

Dispersion: $320 \AA / \mathrm{mm}$ (Grating)

photographic path because of its low altitude, but we happened to know that Messrs. Y. Kashiwagi and Y. Asai photographed the same meteor at Odawara, about $90 \mathrm{~km}$ to the South of Dodaira. Through their kind offer of the film, we could fortunately determine the meteor's aerial path as given in Table 5 .

Table 5

Aerial path of the meteor (Spectrum No. 56)

$\begin{gathered}\text { Ref. No. } \\ \text { of } \\ \text { Measured } \\ \text { Point }\end{gathered}$
1
2
3
4
5
6
7
8

\begin{tabular}{|c|c|}
\hline \multicolumn{2}{|c|}{$\begin{array}{c}\text { Apparent Path at Dodaira } \\
(1950.0)\end{array}$} \\
\hline \multicolumn{2}{|c|}{$\checkmark \quad \delta$} \\
\hline \\
\hline $530 \cdot 4$ & $-8^{\circ} 34^{\prime}$ \\
\hline \multicolumn{2}{|l|}{$514 \cdot 3$} \\
\hline $56 \cdot 3$ & $-11^{\circ} 25^{\prime}$ \\
\hline \multicolumn{2}{|l|}{$5 \quad 4 \cdot 4$} \\
\hline \multirow{2}{*}{\multicolumn{2}{|c|}{$\begin{array}{rr}5 & 1 \cdot 4 \\
4 & 58 \cdot 0\end{array}$}} \\
\hline & $-12^{\circ} 22^{\prime}$ \\
\hline \multicolumn{2}{|l|}{$451 \cdot 5$} \\
\hline
\end{tabular}

Longitude
$138^{\circ} 24^{\prime} \mathrm{E}$
$138^{\circ} 20^{\prime}$
$138^{\circ} 15^{\prime}$
$138^{\circ} 12^{\prime}$
$138^{\circ} 12^{\prime}$
$138^{\circ} 11^{\prime}$
$138^{\circ} 10^{\prime}$
$138^{\circ} 7^{\prime}$

Latitude

Height

Meteor's Coordinates

As seen from Table 5, the meteor was photographed between the heights of $117 \mathrm{~km}$ and $85 \mathrm{~km}$, giving rise to bright flares three times. The brightest position was at the height of $89 \mathrm{~km}$.

The identification of spectral lines, 73 in all, has been made with care, and the results are summarized in Table 6 . In this table the number in the bracket standing at the right side of each row of the last column is the multiplet number given in Moore's multiplet table. In Table 7 the approximate value of each line's relative intensity is given. The values are arranged according to the serial reference number corresponding to those used in Table 6 . The measured values correspond to the meteor's brightest position at a height of $89 \mathrm{~km}$. Over all, in addition to the forbidden line of $\mathrm{OI}$, the lines of eight elements, $\mathrm{Ca}, \mathrm{Si}, \mathrm{Mg}, \mathrm{Na}, \mathrm{Fe}, \mathrm{Co}, \mathrm{Ni}$ and $\mathrm{Cr}$, are found in 
Table 6

Identification of lines (Spectrum No. 56)

Measured Wavelength

1st order 2nd order

Wavelength of Multiplet Table

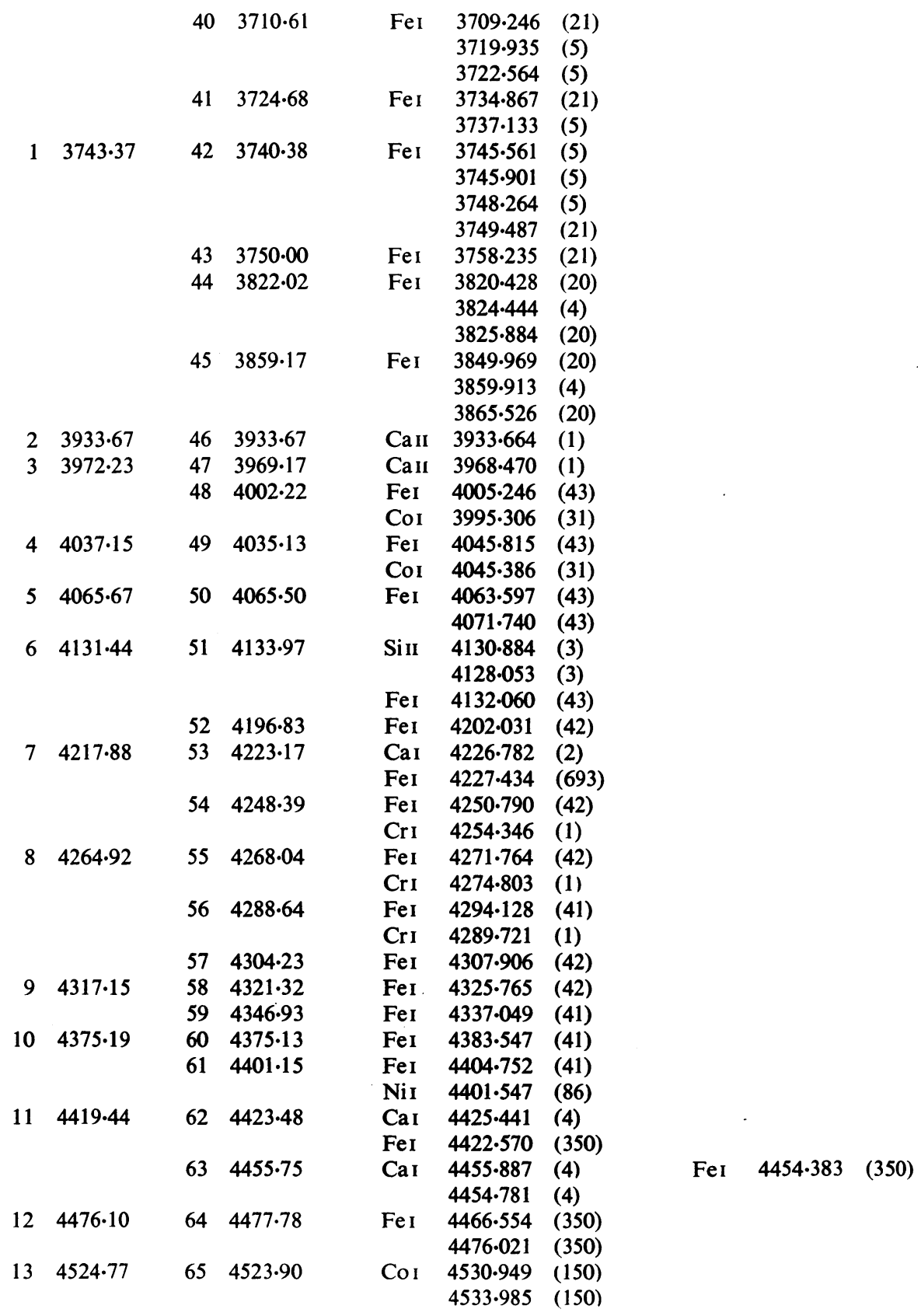


Measured Wavelength

1st order 2nd order

$\begin{array}{llll} & & 66 & 4553 \cdot 78 \\ 14 & 4564.72 & 67 & 4567.01 \\ 15 & 4636.07 & & \\ 16 & 4698.95 & & \\ & & & \\ 17 & 4777.68 & & \\ & & & \\ 18 & 4913.00 & & \\ & & & \\ 19 & 4950.35 & & \\ & & & \\ 20 & 5005 \cdot 71 & & \\ 21 & 5044.50 & & \\ 22 & 5104.79 & & \\ 23 & 5165.29 & 68 & 5163.55\end{array}$

$\begin{array}{ll}69 & 5179.28\end{array}$

$\begin{array}{llll}24 & 5219.68 & 70 & 5224.99\end{array}$

$\begin{array}{llll}25 & 5266 \cdot 30 & 71 & 5265.04\end{array}$

$\begin{array}{llll}26 & 5321.26 & 72 & 5323.21\end{array}$

$\begin{array}{llll}27 & 5365.63 & 73 & 5365.50\end{array}$

$28 \quad 5386.53$

$30 \quad 5448.93$

$31 \quad 5493.63$

$32 \quad 5524 \cdot 76$

$33 \quad 5590 \cdot 46$

$34 \quad 5673 \cdot 83$

$35 \quad 5888 \cdot 86$

$36 \quad 5972 \cdot 04$

$37 \quad 6152 \cdot 76$

$38 \quad 6239 \cdot 91$

$39 \quad 6347.96$
Wavelength of Multiplet Table

\begin{tabular}{|c|c|c|}
\hline CoI & $4549 \cdot 658$ & \\
\hline CoI & 4565.578 & \\
\hline Co I & $4629 \cdot 359$ & \\
\hline \multirow[t]{2}{*}{ CoI } & $4693 \cdot 190$ & \\
\hline & 4698.389 & \\
\hline \multirow[t]{2}{*}{ Cor } & 4768.072 & \\
\hline & $4771 \cdot 108$ & \\
\hline \multirow[t]{2}{*}{$\mathrm{Fe} I$} & 4918.999 & \\
\hline & 4920.509 & \\
\hline \multirow[t]{2}{*}{ Fe I } & $4957 \cdot 302$ & \\
\hline & 4957.603 & \\
\hline $\mathrm{Fe}_{\mathrm{I}}$ & $5006 \cdot 126$ & \\
\hline $\mathrm{Fe}_{\mathrm{I}}$ & $5049 \cdot 825$ & \\
\hline $\mathrm{Fe}_{\mathrm{I}}$ & 5110.414 & (1) \\
\hline \multirow[t]{3}{*}{$\operatorname{Mg}_{I}$} & $5167 \cdot 322$ & (2) \\
\hline & $5172 \cdot 684$ & (2) \\
\hline & 5183.604 & (2) \\
\hline
\end{tabular}

$\dot{F e}_{I} \quad 5226.868 \quad(383)$

$5232.946 \quad(383)$

Fe I $5263.314 \quad(553)$

$5266.562 \quad(383)$

$5269.541 \quad(15)$

Fe I $5324 \cdot 185$ (553)

5328.042 (15)

Fe I 5371.493 (15)

$\mathrm{Fe}_{\mathrm{I}} \quad 5383.628$ (553)

Fe I 5446.920 (15)

5455.613 (15)

FeI 5497.519 (15)

$5501.469 \quad(15)$

CoI $5530.780 \quad$ (38)

CoI 5590.744 (90)

$\mathrm{NaI} 5682.633$ (6)

$5688.205 \quad$ (6)

$\mathrm{Na} I \quad 5888.953$ (1)

5895.923 (1)

Si II 5957.612 (4)

$5978.970 \quad$ (4)

CoI $5991.890 \quad(90)$

$\mathrm{NaI} \quad 6154.225$ (5)

6160.747 (5)

Si I $6237.62 \quad$ (27)

$6243.86 \quad(28)$

$6244.56 \quad$ (27)

$6254.25 \quad(28)$

$6273.34 \quad(28)$

CoI 6230.968 (37)

$6282.636 \quad(37)$

Si II 6347.091 (2)

$6371.359 \quad$ (2) 
Table 6 (Continued)

Measured Wavelength

1st order 2nd order

\begin{tabular}{|c|c|c|c|c|c|c|c|}
\hline \multirow{6}{*}{1} & \multirow{5}{*}{$3743 \cdot 37$} & 40 & \multirow{2}{*}{\multicolumn{2}{|c|}{$\begin{array}{l}3710 \cdot 61 \\
3724.68\end{array}$}} & \multirow{4}{*}{$\begin{array}{c}\mathrm{Fe}_{\mathrm{I}}(5) \\
\downarrow\end{array}$} & \multirow{2}{*}{\multicolumn{2}{|c|}{$\mathrm{Fe}_{I}(21)$}} \\
\hline & & 41 & & & & & \\
\hline & & 42 & $3740 \cdot 38$ & & & & \\
\hline & & 43 & $3750 \cdot 00$ & & & $\downarrow$ & \\
\hline & & 44 & $3822 \cdot 02$ & & $\mathrm{Fe}_{I}(4)$ & $\mathrm{Fel}(20)$ & \\
\hline & & 45 & $3859 \cdot 17$ & & $\downarrow$ & $\downarrow$ & \\
\hline 2 & 3933.67 & 46 & 3933.67 & Ca II (1) & & & \\
\hline 3 & $3972 \cdot 23$ & 47 & $3969 \cdot 17$ & $\downarrow$ & & & \\
\hline & & 48 & $4002 \cdot 22$ & & $\mathrm{Fe}_{\mathrm{I}}$ (43) & & CoI (31) \\
\hline 4 & $4037 \cdot 15$ & 49 & $4035 \cdot 13$ & & & & $\downarrow$ \\
\hline 5 & $4065 \cdot 67$ & 50 & $4065 \cdot 50$ & & & & \\
\hline 6 & 4131.44 & 51 & 4133.97 & Sill (3) & $\downarrow$ & & \\
\hline & & 52 & $4196 \cdot 83$ & & $\mathrm{Fe}_{\mathrm{I}}(42)$ & & \\
\hline 7 & $4217 \cdot 88$ & 53 & $4223 \cdot 17$ & $\mathrm{Cal}$ (2) & & Fe I (693) & \\
\hline & & 54 & $4242 \cdot 39$ & & & & CrI (1) \\
\hline 8 & 4264.92 & 55 & $4268 \cdot 04$ & & & & \\
\hline & & 56 & $4288 \cdot 64$ & & & Fe I (4l) & $\downarrow$ \\
\hline & & 57 & $4304 \cdot 23$ & & & & \\
\hline 9 & $4317 \cdot 15$ & 58 & $4321 \cdot 32$ & & $\downarrow$ & & \\
\hline & & 59 & $4346 \cdot 93$ & & & & \\
\hline 10 & $4375 \cdot 19$ & 60 & $4375 \cdot 13$ & & & & \\
\hline & & 61 & $4401 \cdot 15$ & & & $\downarrow$ & Nil (86) \\
\hline 11 & 4419.44 & 62 & 4423.48 & $\mathrm{CaI}$ (4) & $\mathrm{Fe}_{\mathrm{I}}(350)$ & & \\
\hline & & 63 & $4455 \cdot 75$ & $\downarrow$ & 1 & & \\
\hline 12 & $4476 \cdot 10$ & 64 & $4477 \cdot 78$ & & $\downarrow$ & & \\
\hline 13 & $4524 \cdot 77$ & 65 & $4523 \cdot 90$ & & & & CoI $(150)$ \\
\hline & & 66 & $4553 \cdot 78$ & & & & \\
\hline 14 & $4564 \cdot 72$ & 67 & $4567 \cdot 01$ & & & & $\downarrow$ \\
\hline 15 & 4636.07 & & & & & & Coi (156) \\
\hline 16 & $4698 \cdot 95$ & & & & & & \\
\hline 17 & $4777 \cdot 68$ & & & & & & $\downarrow$ \\
\hline 18 & 4913.00 & & & & $\mathrm{Fe}_{1}(318)$ & & \\
\hline 19 & $4950 \cdot 35$ & & & & 1 & & \\
\hline 20 & $5005 \cdot 71$ & & & & $\downarrow$ & & \\
\hline 21 & $5044 \cdot 50$ & & & & $\mathrm{Fe} I(114)$ & & \\
\hline 22 & $5104 \cdot 79$ & & & & $\mathrm{Fe}_{1}(1)$ & & \\
\hline 23 & 5165.29 & 68 & $5163 \cdot 55$ & $M g I(2)$ & & & \\
\hline & & 69 & 5179.28 & $?$ & & & \\
\hline 24 & 5219.68 & 70 & 5224.99 & & $\mathrm{Fe}_{1}(15)$ & $\mathrm{Fe}$ I (383) & $\mathrm{Fe}_{\mathrm{I}}(553)$ \\
\hline 25 & $5266 \cdot 30$ & 71 & 5265.04 & & & $\downarrow$ & \\
\hline 26 & $5321 \cdot 26$ & 72 & $5323 \cdot 21$ & & & & \\
\hline 27 & $5365 \cdot 63$ & 73 & $5365 \cdot 50$ & & & & \\
\hline 28 & 5386.53 & & & & & & $\downarrow$ \\
\hline 30 & 5448.93 & & & & & & \\
\hline 31 & $5493 \cdot 63$ & & & & $\downarrow$ & & \\
\hline 32 & $5524 \cdot 76$ & & & & & & CoI (38) \\
\hline 33 & $5590 \cdot 46$ & & & & & & Co I (90) \\
\hline 34 & 5673.83 & & & $\mathrm{Na}$ ( (6) & & & \\
\hline 35 & $5888 \cdot 86$ & & & $\mathrm{Na}$ ( (1) & & & \\
\hline 36 & 5972.04 & & & Si II (4) & & & $\downarrow$ \\
\hline 37 & 6152.76 & & & $\mathrm{NaI}$ & & & \\
\hline 38 & 6239.91 & & & Si I (27), (28) & & & Cor (37) \\
\hline 39 & $6347 \cdot 96$ & & & Sill (2) & & & \\
\hline
\end{tabular}

Element and Multiplet

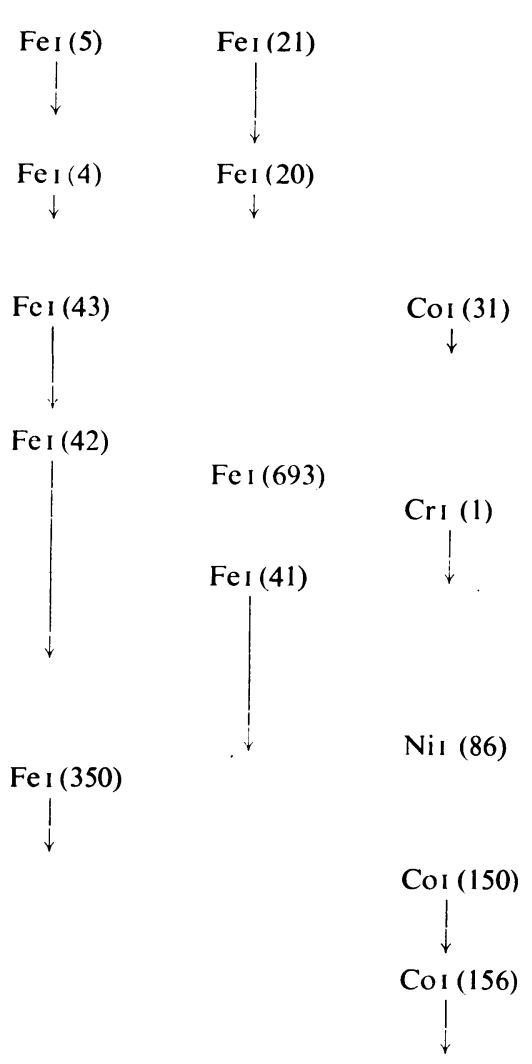


Table 7

Relative intensities of the spectral lines at the brightest point (Spectrum No. 56)

$\begin{array}{rrrrrr}\text { No. } & \text { Intensity } & \text { No. } & \text { Intensity } & \text { No. } & \text { Intensity } \\ 1 & 43 & 25 & 72 & 50 & 57 \\ 2 & 100 & 26 & 71 & 51 & 46 \\ 3 & 92 & 27 & ? & 52 & 48 \\ 4 & 49 & 28 & ? & 53 & 55 \\ 5 & 44 & 29 & ? & 54 & 45 \\ 6 & 45 & 30 & ? & 55 & 51 \\ 7 & 54 & 31 & 49 & 56 & 42 \\ 8 & 52 & 32 & 50 & 57 & 43 \\ 9 & 49 & 33 & 59 & 58 & 45 \\ 10 & 58 & 34 & 55 & 59 & 32 \\ 11 & 53 & 35 & 101 & 60 & 83 \\ 12 & 58 & 36 & 47 & 61 & 64 \\ 13 & 50 & 37 & 56 & 62 & 72 \\ 14 & 52 & 38 & 57 & 63 & 72 \\ 15 & 50 & 39 & 65 & 64 & 73 \\ 16 & 53 & 40 & 58 & 65 & 85 \\ 17 & 51 & 41 & 64 & 66 & 59 \\ 18 & 44 & 42 & 70 & 67 & 58 \\ 19 & 40 & 43 & 54 & 68 & 57 \\ 20 & 49 & 44 & 66 & 69 & 57 \\ 21 & 47 & 45 & 67 & 70 & ? \\ 22 & 47 & 46 & 132 & 71 & ? \\ 23 & 84 & 47 & 121 & 72 & ? \\ 24 & 68 & 48 & 49 & 73 & ? \\ & & 49 & 56 & & \end{array}$

this meteor spectrum at the height of $89 \mathrm{~km}$. The detailed and extensive analysis of this spectrum is still in progress.

\section{Preliminary Conclusions}

As to the observational optical study of meteor physics, our experience has taught us that the accumulation of more spectrograms of high quality is important at the present stage. This opinion demands a longer observation time in practice, and we are planning to convert our automatic photographic cameras, situated at Dodaira, into spectral ones, with the use of transmission gratings. This will make a long time of observation easier and simpler. The grating camera is far more useful than the prism camera because the zero-order image of the former can be treated as that of a direct photograph, if the meteor is bright enough. We think such an improvement will be useful in every branch of meteor study.

Another important item is to study meteor spectra in the infrared region, especially the behavior of the SiII lines at $6347 \AA$ and $6371 \AA$. We think the study of the meteor's infrared spectrum will give valuable information about the abundance of 
silicon, and new clues as to the relation between the radiation mechanism of meteors and the upper atmosphere.

\section{References}

Ceplecha, Z. (1961) Bull. astr. Inst. Csl., 12, 246.

Ceplecha, Z. (1964) Bull. astr. Inst. Csl., 15, 102.

Ceplecha, Z., Rajchl, J. (1963) Bull. astr. Inst. Csl., 14, 29.

Cook, A.F., Millman, P. M. (1955) Astrophys. J., 121, 250.

Halliday, I. (1958) Astrophys. J., 128, 441.

Hirose, H. (1951) Tokyo astr. Obs. Rep., 36, 11.

Lovell, A.C.B. (1954) Meteor Astronomy, Clarendon Press, Oxford.

Millman, P. M. (1932) Ann. Harv. Coll. Obs., 82, 113.

Millman, P. M. (1932) Ann. Harv. Coll. Obs., 82, 149.

Millman, P. M., Cook, A.F. (1959) Astrophys. J., 130, 648.

Millman, P.M., McKinley, D.W.R. (1963) Meteors, in The Solar System, IV, ed. by B. M. Middlehurst and G.P. Kuiper, Univ. of Chicago Press, p. 674.

Rajchl, J. (1964) Bull. astr. Inst. Csl., 15, 138. 